\title{
Idiopathic adulthood ductopenia manifesting as jaundice in a young male
}

\author{
Deepak Jain ${ }^{\star, 1}$, H. K. Aggarwal ${ }^{1}$, Avinash Rao ${ }^{1}$, Shaveta Dahiya ${ }^{1}$, Promil Jain ${ }^{2}$ \\ ${ }^{1}$ Department of Medicine, Pt. B.D. Sharma University of Health Sciences, Rohtak (Haryana), India, \\ ${ }^{2}$ Department of Pathology, Pt. B.D. Sharma University of Health Sciences, Rohtak (Haryana), India
}

\begin{abstract}
Idiopathic adulthood ductopenia (IAD) is an unusual disease of unknown etiology which results in chronic cholestatic liver disease. It manifests in young or middle aged adults and is characterized by absence of specific autoantibodies and a loss of interlobular bile ducts. It is a rare cause of cholestatic jaundice with less than 100 cases reported worldwide. We report a case of 18 year male patient who was diagnosed to be suffering from IAD based on clinical, pathological and radiological investigations.
\end{abstract}

Keywords: idiopathic adulthood ductopenia, cholestatic liver disease

\section{Introduction}

Idiopathic adulthood ductopenia (IAD), for the first time, was reported in 1988 [1]. The disease is to be suspected when young to middle aged adults present with obstructive jaundice of medical cause. The evidence of ductopenia in liver biopsy or cholangiographic evidence of paucity of bile ducts leads to confirmation of diagnosis. Exclusion of other conditions with chronic cholestasis that are associated with ductopenia is very much needed to support the diagnosis of IAD [2].

We report a case of a young male patient suffering from IAD with a brief insight to the etiology, pathogenesis and treatment options of the disease.

Received: January 2016; Accepted after review: March 2016; Published: March 2016.

${ }^{*}$ Corresponding author: Assist. Prof. Dr. Deepak Jain, Department of Medicine, Pt. B.D. Sharma University of Health Sciences, Rohtak-124001, (Haryana), India. Phone: +91-9416147887

Email: jaindeepakdr@gmail.com

\section{Case Report}

An 18 year male patient presented to outpatient department with history of jaundice and itching all over the body since 6 months. Jaundice was progressive non-fluctuating associated with yellowish urine, clay colored stools. There was history of intense, progressive pruritus. There was no past history of tuberculosis, diabetes, hypertension, blood transfusion, intake of indigenous medications, family members suffering from similar illness.

On general examination, icterus was present. There were visible scratch marks over limbs and trunk (Figure 1). Abdominal examination revealed mild hepatosplenomegaly. Rest systemic examination including cardiovascular, respiratory and nervous systems, was normal. On the day of hospital admission laboratory examination revealed that the patient was anemic with hemoglobin of $9.6 \mathrm{~g} / \mathrm{dL}$. Active inflammatory status was denoted by erythrocyte sedimentation rate of $50 \mathrm{~mm} / 1^{\text {st }}$ hour. 


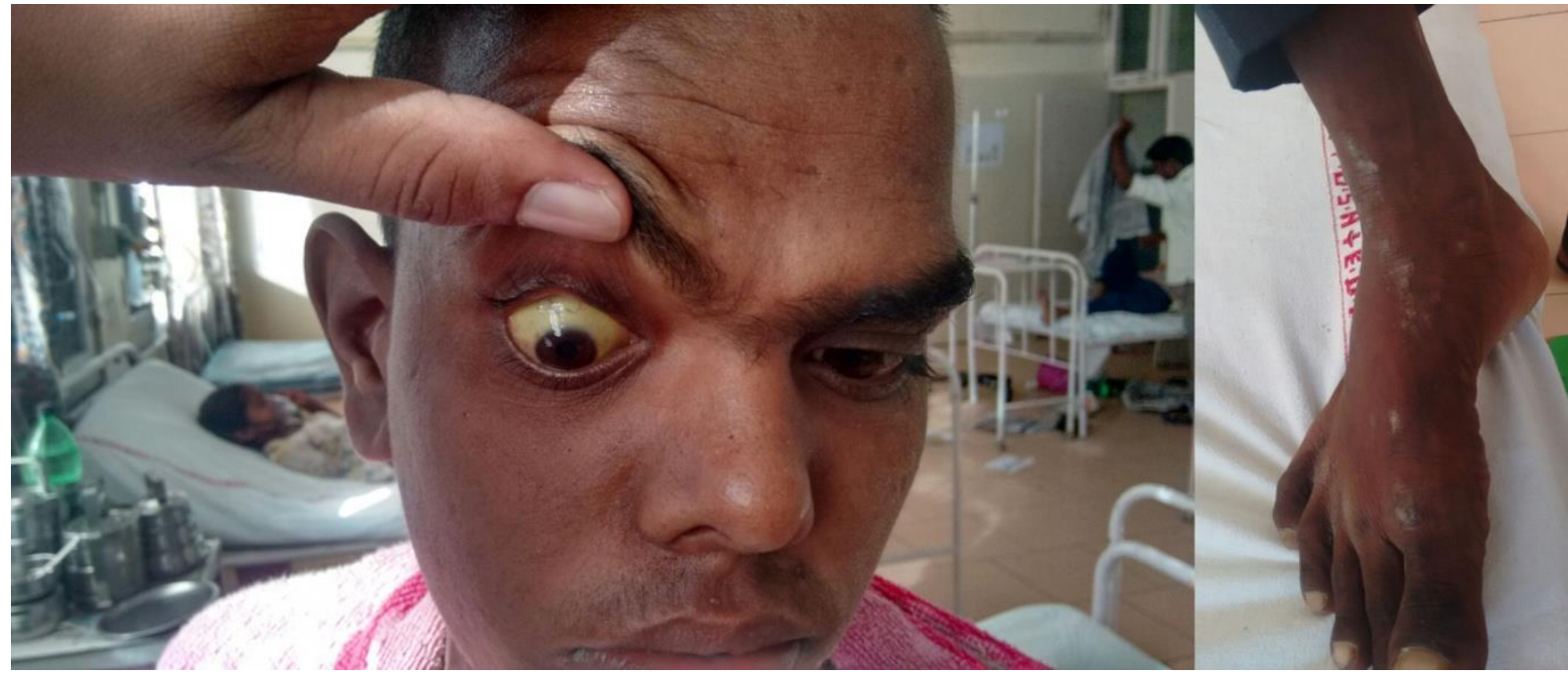

Fig. 1. File picture of the patient at presentation. Yellowish discoloration of sclera and scratch marks on the leg are visible.

Liver function tests were deranged with serum aspartate aminotransferase $123 \mathrm{U} / \mathrm{L}$ (normal up to 40), serum alanine aminotransferase $135 \mathrm{U} / \mathrm{L}$ (normal up to 40 ), serum bilirubin $19.3 \mathrm{mg} / \mathrm{dl}$ (normal, 0.2-0.8, direct $-11 \mathrm{mg} / \mathrm{dl}$, indirect $-8.3 \mathrm{mg} / \mathrm{dl}$ ), serum alkaline phosphatase $311 \mathrm{U} / \mathrm{L}$ (normal, 39117), serum gamma glutamyl transpeptidase $520 \mathrm{U} / \mathrm{L}$ (normal, 5-40), total serum proteins $5.2 \mathrm{~g} / \mathrm{dl}$ (normal, 6-8), serum triglycerides 170 $\mathrm{mg} / \mathrm{dl}$ (normal, 60-160), serum cholesterol 247 $\mathrm{mg} / \mathrm{dl}$ (normal, 130-230), serum high density lipoproteins $30 \mathrm{mg} / \mathrm{dl}$ (normal, 30-60), serum low density lipoproteins $155 \mathrm{mg} / \mathrm{dl}$ (normal up to 160 ) and serum very low density lipoproteins $40 \mathrm{mg} / \mathrm{dl}$ (normal, 16-32). Renal function tests were normal. Random blood sugar was $100 \mathrm{mg} / \mathrm{dl}$. Malaria antibodies were absent. Viral markers for HIV, Hepatitis A, B, C and $E$ were negative. Urine complete examination was normal.

Investigations for hereditary and autoimmune diseases including serum ceruloplasmin level, serum ferritin, serum transferrin saturation, anti-mitochondrial antibodies were within normal range. Antinuclear antibodies, p-ANCA and anti LKM antibodies were absent.
Ultrasonography of the abdomen revealed hepatosplenomegaly, with liver measuring $16.3 \mathrm{~cm}$ and spleen measuring $13.5 \mathrm{~cm}$. Upper gastrointestinal endoscopic study was normal. Chest $X$ ray of the patient was normal (Figure 2). An abdominal CT showed normal echogenicity of the liver. No evidence of cholelithiasis or biliary dilation was noted.

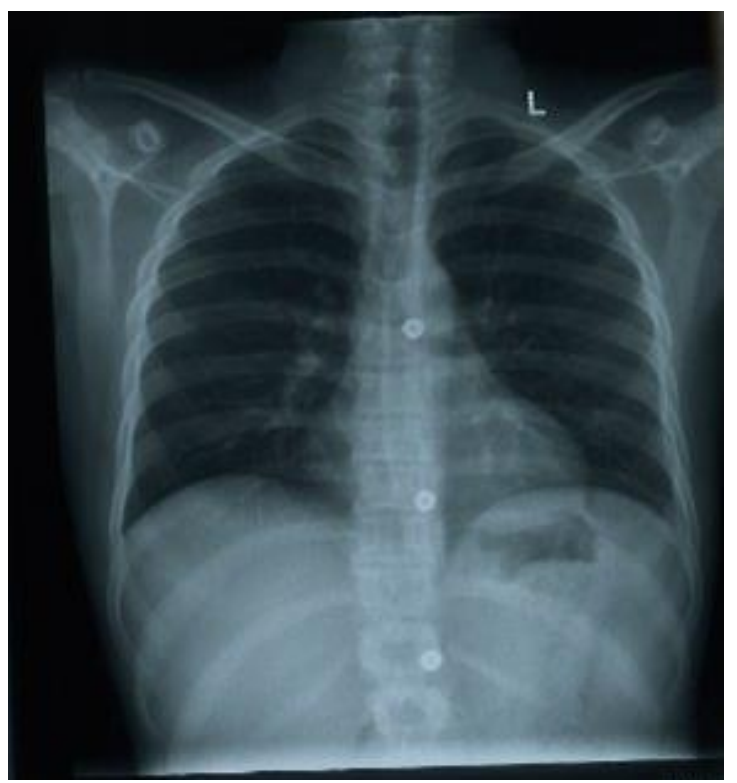

Fig. 2. Normal chest $\mathrm{X}$-ray of the patient. 
In the course of patient's follow up in the next 6 months, serum aminotransferase levels, alkaline phosphatase levels and serum GGT levels remained persistently high.

As the routine laboratory investigations gave no clue regarding the symptoms, a percutaneous liver biopsy was done. The histopathology revealed absence of interlobular bile ducts with mild inflammatory infiltrate. There was presence of feathery degeneration with intra-cytoplasmic bile pigment accumulation (Figure 3). Based on the presentation, histopathology and the radiological investigations, the patient was labeled to be suffering from Idiopathic Adulthood Ductopenia. Patient was started on oral ursodeoxycholic acid $450 \mathrm{mg}$ twice daily with vitamin supplements. Patient is being routinely followed up in the outpatient clinic.

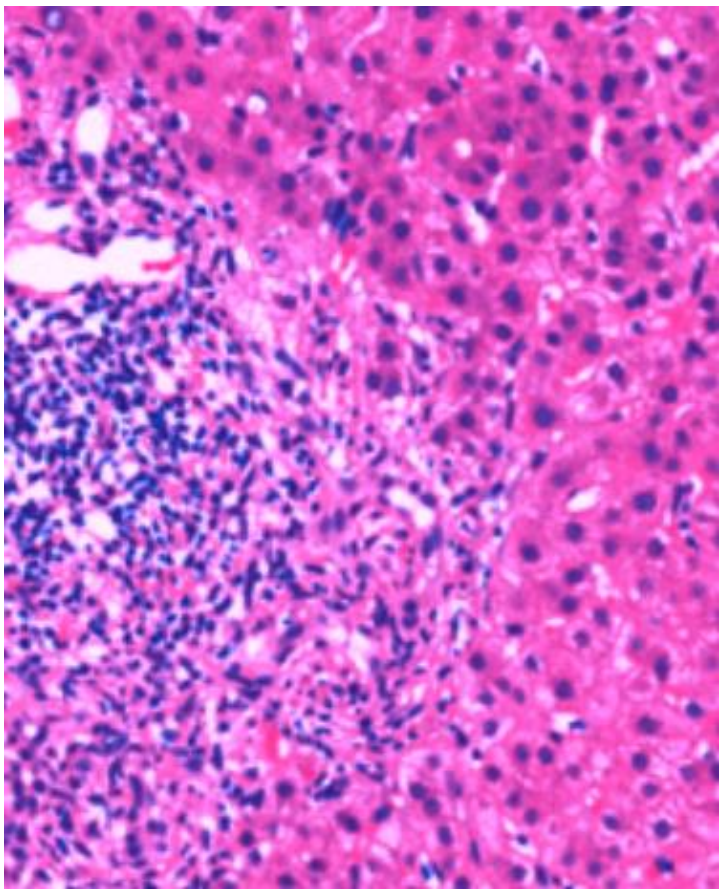

Fig. 3. Histopathology picture revealing absence of interlobular bile ducts with mild inflammatory infiltrate (HE, x400).

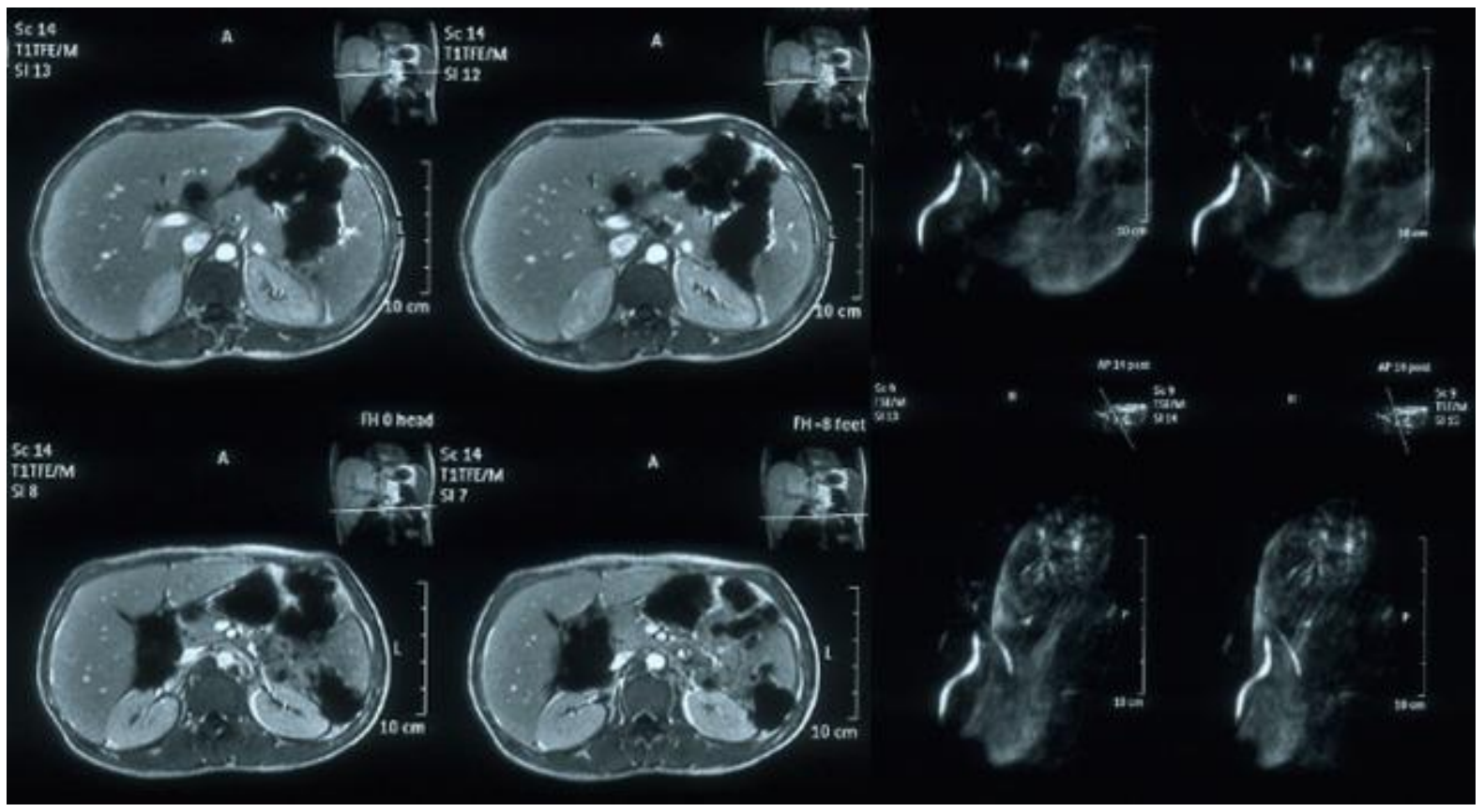

Fig. 4. MRCP of the patient revealing paucity of intrahepatic bile duct indicating ductopenia with thinning of bile ductules.

\section{Discussion}

IAD is a rare entity which is to be suspected in young and middle aged adults who present with medical jaundice of unknown etiology. Common etiologies of chronic cholestasis must be excluded before confirmation of diagnosis, as IAD is a diagnosis of exclusion. The disease is a part of small biliary duct diseases and the major 
diseases affecting these ducts as primary biliary cirrhosis (PBC) and primary sclerosing cholangitis (PSC) are to be ruled out before labeling IAD [3].

Although the cause of IAD remains to be elucidated, the proposed etiological factors in the literature include autoimmune diseases, viral hepatitis, auto-inflammatory diseases, variant presentation of PSC, non-suppurative viral cholangitis $[4,5]$. Whether genetics play a role in the pathogenesis of the disease is to be addressed in the further studies.

The gold standard investigation for diagnosis of IAD is liver biopsy. Ductopenia is the necessary criterion which is defined as paucity of interlobular and septal bile ducts among 20 or more portal tracts. Depending on the prognosis IAD could be classified into two different types. Type 1 IAD, a benign entity with paucity of bile ducts is less than $50 \%$. In type 2 IAD, patients will have more extensive ductopenia, rapidly progressive liver disease characterized by decompensated biliary cirrhosis $[4,6]$.

The possible mechanism for the disease predominance in young and middle aged adults could be an underlying genetic component which gets triggered by an inciting event such as infection or immunological phenomenon after a period of environmental exposure. A multidisciplinary approach is to be undertaken in defining the etio-pathogenesis of IAD.

In our patient, the query of IAD came up after ruling out almost every etiology related to chronic cholestasis and evidence of ductopenia in the MRCP. Percutaneous liver biopsy was then carried out which showed a confirmatory evidence of ductopenia. So, the radiological evidence could be added to the diagnostic criteria as it could avoid or supplant painful biopsy procedure in the patients suffering from IAD.

Treatment for IAD depends on the etiology and the severity of the clinical course. In

\section{References}

1. Ludwig J, Wiesner $\mathrm{RH}$, LaRusso NF. Idiopathic adulthood ductopenia: a cause of chronic patients with non-progressive (mainly type 1) $I A D$, UDCA has been shown to improve liver enzymes. On the other hand, patients with progressive diseases, and those with advanced cases, will ultimately require orthotopic liver transplantation [7].

In the case presented, the cause of the ductopenia remained unknown. It could be attributed to interplay between various factors mentioned above. Patient is presently being followed up in the routine clinic. As IAD typically progresses to end stage liver disease, patient has been advised for liver transplantation in the course of the treatment.

\section{Conclusion}

Only few cases of IAD have been reported in the literature. Future studies are to be undertaken to find the cause of the disease and solve the enigma behind the pathogenesis. The clinical interest in presenting this case is to make the treating physicians aware that there is an emergence of this rare entity as a differential diagnosis for the medical cause of obstructive jaundice. MRCP could be of value in replacing painful liver biopsy for the diagnosis of ductopenia. As the disease manifests in young and middle aged adults, efforts have to be made to discover the effective modalities of treatment to halt or nullify its progression.

\section{Consent}

Written informed consent was obtained from the patient for publication of this case report and accompanying images.

\section{Conflict of interest}

The author(s) declare that they have no competing interests.

cholestatic liver disease and biliary cirrhosis. $J$ Hepatol 1988; 7:193-199. 
2. Park BC, Park SM, Choi EY, et al. A Case of Idiopathic Adulthood Ductopenia. Korean J Internal Med 2009; 24:270-273.

3. Ludwig J. Idiopathic adulthood ductopenia: an update. Mayo Clin Proc 1998; 73:285-291.

4. Khanlou H, Sass D, Rothstein $K$, et al. Idiopathic adulthood ductopenia: case report and review of the literature. Arch Intern Med 2000; 160:1033-1036.

5. Dural AT, Genta RM, Goodman ZD, Yoffe B. Idiopathic adulthood ductopenia associated with hepatitis C virus. Dig Dis Sci 2002; 47:1625-1626.

6. Moreno A, Carreno V, Cano A, Gonzalez C. Idiopathic bilary ductopenia in adults without symptoms of liver diseases. $N$ Engl $J$ Med 1997; 33:835-838.

7. Kaung A, Sundaram V, Dhall D, Tran TT. A case of mild idiopathic adulthood ductopenia and brief review of literature. Gastroenterol Rep 2015; 3(2):167-169. 